\title{
Are all adverse effects undesirable? a case of chemotherapy induced adverse effect- an exception!?
}

\author{
Divyashanthi Chellathambi Malathi*, Raman Palanisamy Priyadharsini, Dhivya Elango
}

Department of Pharmacology, JIPMER, Karaikal, Puducherry, India

\author{
Received: 18 March 2021 \\ Revised: 28 September 2021 \\ Accepted: 29 September 2021 \\ *Correspondence: \\ Dr. Divyashanthi Chellathambi Malathi, \\ Email: dishanthii@gmail.com
}

Copyright: $(\subseteq)$ the author(s), publisher and licensee Medip Academy. This is an open-access article distributed under the terms of the Creative Commons Attribution Non-Commercial License, which permits unrestricted non-commercial use, distribution, and reproduction in any medium, provided the original work is properly cited.

\begin{abstract}
Targeted cancer therapies, a recent development in cancer chemotherapy are drugs that block the growth and spread of cancer by interfering with specific molecules which are responsible for the progression of cancer, among which tyrosine kinase inhibitors play an important role. Erlotinib is a tyrosine kinase inhibitor that targets the epidermal growth factor receptor and is a promising drug for the treatment of non-small cell lung cancers and unresectable metastatic pancreatic cancers. Adverse drug reactions are noxious and unintended responses to drugs that occur at doses normally used in man. Cancer chemotherapeutics are well known to cause a wide range of adverse effects from mild to serious ones. All anticancer drugs cause alopecia, gastrointestinal disturbances, skin and hair changes as they affect all the rapidly proliferating cells in addition to cancer cells. Erlotinib causes some less serious adverse effects, one of which is trichomegaly which is presented here in this case report. Though adverse reactions are generally undesirable, trichomegaly induced by erlotinib could be considered as a marker of good tumor response to treatment and a positive outcome. Moreover, this adverse effect could be exploited in the treatment of madarosis for which currently, treatment options are very few.
\end{abstract}

Keywords: Targeted cancer therapy, Trichomegaly, Favourable, Adverse drug reaction, Madarosis

\section{INTRODUCTION}

Targeted anti-cancer therapy, a recent advancement has led to significant breakthroughs in cancer treatment, which specifically targets the cancer cells thus minimizing the adverse effects. EGFR (Epidermal growth factor receptor) inhibitors are one such targeted agent used in the treatment of a wide variety of cancers which includes non-small cell lung cancers, pancreatic cancers, colorectal cancers, gastric cancers etc.

Erlotinib, a tyrosine kinase EGFR inhibitor, is approved by the FDA for first-line treatment of patients with metastatic Non-small cell lung cancer (NSCLC) with EGFR mutations; maintenance therapy of patients with NSCLC and no evidence of disease progression after 4 cycles of platinum-based first-line chemotherapy; and treatment of NSCLC after the failure of $\geq 1$ prior chemotherapy regimen. It is approved as the first-line treatment of patients with locally advanced/metastatic pancreatic cancer, in combination with gemcitabine. ${ }^{1}$ Eyelash trichomegaly is defined as an increase in length $(12 \mathrm{~mm}$ or more), curling, pigmentation or thickness of eyelashes. ${ }^{2}$ Various causes of trichomegaly include congenital, familial, acquired and drugs. There is a list of drugs that can cause trichomegaly which include phenytoin, diazoxide, minoxidil, acetazolamide, tacrolimus, cyclosporine, topiramate and prostaglandin analogues. Eyelash trichomegaly can be psychologically disturbing and may lead to corneal abrasions and visual disturbances if trichiasis occurs. ${ }^{3}$

\section{CASE REPORT}

Here we present a case of a 51-years-old woman diagnosed with NSCLC with positive EGFR mutation and 
was started on Erlotinib treatment. She was on treatment for three months and during the treatment, her symptoms of dyspnoea, cough and productive sputum improved. But she developed discomfort in visualizing things especially reading books, as her lengthy eyelashes rubbed against her spectacles and obscured her vision.

On her next visit to the hospital, the diagnosis of trichomegaly was confirmed and her eyelashes were trimmed by an ophthalmologist. Two weeks later, the patient presented again to the ophthalmology OPD to get her eyelashes trimmed. The patient was much worried about the loss of hair over her scalp and the excessive growth of eyelashes and hair growth all over her face.

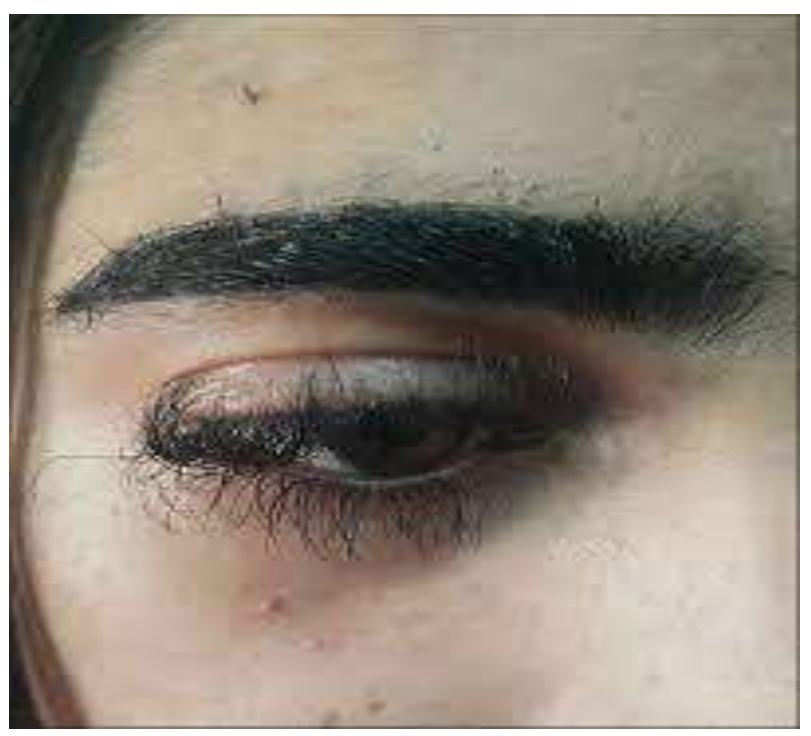

Figure 1: Internet downloaded for demonstration.

\section{DISCUSSION}

Generally, all anticancer drugs affect the rapidly proliferating cells like hair follicles, gastric mucosa, skin and nails apart from cancer cells. Alopecia and skin changes are very common with cancer chemotherapeutic agents.

EGFR is located in the hair follicles, especially its outer root sheath and plays an important role in regulating the hair cycle. ${ }^{4}$ Erlotinib, an EGFR inhibitor, specifically causes loss of scalp hair whereas it causes excessive growth of eyelashes because eyelashes have a very short anagen phase and a long telogen phase in contrast to scalp hair. ${ }^{5}$ The EGFR signaling inhibition by Erlotinib disrupts the progression of the anagen to the telogen phase and subsequently can stimulate the formation of the disorganized hair follicles resulting in trichomegaly. ${ }^{6,7}$

It is evident from previous reports that erlotinib induced acneiform rash is associated with favourable tumor response and improvement in patient survival. ${ }^{8,9}$ Similarly, trichomegaly observed in cancer patients on erlotinib treatment, also showed that they had a positive response to
anti-EGFR therapy. ${ }^{10}$ Hence, this typical adverse effect of erlotinib induced trichomegaly could be considered as a predictor of better treatment outcome

\section{CONCLUSION}

Adverse effects are generally unwanted and undesirable, yet the adverse effect encountered by the patient in this report could be considered as a marker of clinical outcome. Extensive studies in this aspect, are needed to confirm this. Further, this typical adverse effect of erlotinib could be used to formulate a topical preparation to treat patients with madarosis (loss of eyebrows and eyelashes). Currently prostaglandin analogue, bimatoprost is the only FDA approved drug for the treatment of madarosis. Future research in this aspect would help us to develop the least toxic topical formulation for the treatment of madarosis.

\section{Funding: No funding sources \\ Conflict of interest: None declared \\ Ethical approval: Not required}

\section{REFERENCES}

1. Tsimberidou AM. Targeted therapy in cancer. Cancer Chemother Pharmacol. 2015;76(6):1113-32.

2. Gray H. Trichomegaly or movie lashes. Stanford Med Bull. 1944;2:157-8.

3. Wang SB, Lei KJ, Liu JP, Jia YM. Eyelash trichomegaly following treatment with erlotinib in a non-small cell lung cancer patient: A case report and literature review. Oncol Lett. 2015;10(2):954-6.

4. Albanell J, Rojo F, Averbuch S, Feyereislova A, Mascaro JM, Herbst R, et al. Pharmacodynamic studies of the epidermal growth factor receptor inhibitor ZD1839 in skin from cancer patients: histopathologic and molecular consequences of receptor inhibition. J Clin Oncol. 2002;20(1):110-24.

5. Rosenberger BR, Albert M. Acquired trichomegaly with topiramate. J Am Acad Dermatol. 2005;53(2):362-3.

6. Vergou T, Stratigos AJ, Karapanagiotou EM, Matekovits AE, Dilana KD, Tsimboukis $\mathrm{S}$, et al. Facial hypertrichosis and trichomegaly developing in patients treated with the epidermal growth factor receptor inhibitor erlotinib. J Am Acad Dermatol. 2010;63(2):56-8.

7. Hansen LA, Alexander N, Hogan ME, Sundberg JP, Dlugosz A, Threadgill DW, et al. Genetically null mice reveal a central role for epidermal growth factor receptor in the differentiation of the hair follicle and normal hair development. Am J Pathol. 1997;150(6):1959-75.

8. Westphalen CB, Kukiolka T, Garlipp B, Hahn L, Fuchs M, Malfertheiner P, et al. Correlation of skin rash and overall survival in patients with pancreatic cancer treated with gemcitabine and erlotinib - results from a non-interventional multi-center study. BMC Cancer. 2020;20(1):155. 
9. Soler R, Chachoua A, Hammond LA, Rowinsky EK, Huberman M, Karp D, et al. Determinants of tumor response and survival with erlotinib in patients with non--small-cell lung cancer. J Clin Oncol. 2004;22(16):3238-47.

10. Jeon SH, Ryu JS, Choi GS, Kim JS, Kwon HY, Kim MS, et al. Erlotinib induced trichomegaly of the eyelashes. Tuberc Respir Dis. 2013;74(1):37-40.
Cite this article as: Malathi DC, Priyadharsini RP, Elango D. Are all adverse effects undesirable? a case of chemotherapy induced adverse effect- an exception!?. Int J Basic Clin Pharmacol 2021;10:1308-10. 